\title{
Can science in China do more for conservation?
}

\author{
John R. Fellowes, Michael W.N. Lau and Bosco P.L. Chan
}

China is of unique importance in conservation, both for the biodiversity it contains and for its influence on the world's biota. Science has made many contributions to conserving China's biodiversity, such as mapping species and vegetation types, informing creation of protected areas, and documenting species' trends (Wang et al., 2004; Li \& Smith, 2005; Li Y. et al., 2007) and status (Wang \& Xie, 2004). Yet science has been slow to reveal the wider impacts of consumption in China, and unable to stem an array of devastating internal pressures (Tilson et al., 2004; Li H. et al., 2007; Turvey, 2008). Could conservation scientists improve their contribution? We see several dimensions to this.

Firstly, conservationists must bolster their influence in society. China needs more amateur naturalists; recent illustrated guidebooks (MacKinnon et al., 2000; Smith \& Xie, 2008) and websites (http://www.chinabirdnet.org) have indicated the demand and potential. The country also needs awareness-raisers on ecological heritage, services, status and threats. Science journalists are much needed in the media (Jia, 2007), and scientists can help keep them informed, as well as targeting policy and decision makers. Part of this influence must be ethical. Operating pragmatically within a utilitarian society, and recognizing the needs of stakeholders, does not mean surrendering biocentric values, which only conservationists are likely to represent. Values will not be changed by superficial 'propaganda'deeper engagement is needed (Hau, 2005; Reading, 2005).

Secondly, conservationists need to improve the management relevance of research. Articles on biodiversity can be disappointing for those charged with conserving it; such categorical and quantitative details as vegetation type, alpha diversity and biogeographical affiliation are typically given with no guidance for effective stewardship. Biologists would do well to examine the CBD 2010 targets for direction; in China's disturbed ecosystems the dimension of integrity vs degradation is particularly in need of debate, definition, monitoring and action. More locally, there is need to interpret lists of species in terms of their dependence on particular sites, and to integrate species-specific findings into the ecosystem focus of protected area managers. Officials need ecological advice, in lay language, on many issues: the impacts of building a road or dam, or of harvesting fish, frogs, rattan, fungi, honey or herbs, the severity of threats from invasive species, the effectiveness of possible solutions to hunting, restoration goals and techniques, and more.

John R. Fellowes ${ }^{*}$, Michael W.N. Lau and Bosco P.L. Chan ${ }^{\dagger}$ Kadoorie Farm \& Botanic Garden, Hong Kong, China. E-mail kfjrf@kfbg.org

${ }^{\star}$ Also at: School of Social Sciences and Law, Oxford Brookes University, UK

${ }^{\dagger}$ Also at: Yinggeling Nature Reserve, Baisha, Hainan, China
A third, related dimension is study design, methodology and reporting (McGowan, 2007). Despite the work of journals such as Oryx in encouraging the work of Chinese conservationists, their submissions to international journals have low acceptance rates. This is not simply a language problem, although of course language is a factor-and arguably a whole editing guild is missing from research plans and budgets. Good international journals require strong logical consistency of methods, results and discussion, and this can be a stumbling block. Throughout Asia many scientists publish in local journals. This facilitates sharing of locally important information but can allow bad habits to go unchallenged. Misleading conclusions can arise from inadequate sampling replication and sample size, or sketchy methodological detail, and some conservation concepts have been widely misunderstood. International journals also expect even-handed consideration of others' findings, which often go uncited in local publications.

Conservation involves many people with a variety of strengths. Among the most important are the officials in charge of protected areas. Such officials often have limited scientific background and, without good ecological advice, even the best-intentioned may make decisions harmful to biodiversity. In China officials have generally been slow to approach scientists for advice (MacKinnon, 2007) but if they can find helpful advisers the benefits to their work will be long-lasting. However, those most familiar with a nature reserve and the local biota may not be those best equipped to design applied studies. Conversely, a scientist from a distant city-Beijing or elsewhere-may bring strong academic training, tools and reporting skills, but be disconnected from a reserve and its problems and lack knowledge of the local literature. All these professions need to work together. Some of the most useful environmental publications have come through diverse partnerships, such as those of the China Council for International Cooperation on Environment and Development (http://www.cciced.org). By pooling knowledge, perspectives and skills, many realworld conservation problems can be addressed.

Finally, then-and pertinent in addressing all the above points-we should all aim to improve our collaboration.

The present issue of Oryx illustrates what collaboration can contribute, whilst indicating the scale of problems it must contend with. Zhang et al. (2009) report the sharp declines in an undervalued group of mammals, the bats, and outline steps for addressing them. Gong et al. (2009) show how the devastating trade in turtles for food is being joined by a growing pet trade, and call for better enforcement. Other articles look in depth at some of China's most threatened species. On the Tibetan Plateau, Bleisch et al. 
(2009) record the impact, and recent easing, of poaching pressure on the Tibetan antelope, and Fox et al. (2009) describe the emerging threat from modern range management practices. Chen et al. (2009) throw light on the status of the Chinese crested tern, and urge control of egg poaching. Fan et al. (2009) explore habitat use by the black crested gibbon in Yunnan, reinforcing the value of primary forest, and Chu \& Jiang (2009) provide an update on the rare Sino-Mongolian beaver as it contends with reduced water levels and increased competition with humans. Finally we hear how the conservation of that archetypal flagship species, the giant panda, was hampered by the 2008 earthquake and how habitat fragmentation, synchronous bamboo flowering and die-off, and mismanagement of Nature Reserves are continuing challenges (Ran et al., 2009).

The loss of the baiji (Turvey, 2008) should be our wakeup call: the most priceless assets, of China and the world, are not guaranteed. We are still a long way from achieving harmony for nature and society, and good science has a key place alongside good intentions.

\section{References}

Bleisch, W.V., Buzzard, P.J., Zhang, H., Xu, D., Liu, Z., Li, W. \& Wong, H. (2009) Surveys at a Tibetan antelope Pantholops hodgsonii calving ground adjacent to the Arjinshan Nature Reserve, Xinjiang, China: decline and recovery of a population. Oryx, 43, 191-196.

Chen, S., Chang, S., Liu, Y., Chan, S., Fan, Z., Chen, C. et al. (2009) A small population and severe threats: status of the Critically Endangered Chinese crested tern Sterna bernsteini. Oryx, 43, 209-212.

Chu, H. \& Jiang, Z. (2009) Distribution and conservation of the Sino-Mongolian beaver Castor fiber birulai in China. Oryx, 43, 197-202.

Fan, P., Jiang, X. \& Tian, C. (2009) The Critically Endangered black crested gibbon Nomascus concolor on Wuliang Mountain, Yunnan, China: the role of forest types in the species's conservation. Oryx, 43, 203-208.

Fox, J.L., Dhondup, K. \& Dorji, T. (2009) Tibetan antelope Pantholops hodgsonii conservation and new rangeland management policies in the western Chang Tang Nature Reserve, Tibet: is fencing creating an impasse? Oryx, 43, 183-19o.

Gong, S., Chow, A.T., Fong, J.J. \& ShI, H. (2009) The chelonian trade in the largest pet market in China: scale, scope and impact on turtle conservation. Oryx, 43, 213-216.

HAU, B.C.H. (2005) Environmental education in protected areas in China. Living Forests, 10, 16-18.

JiA, H. (2007) The Crisis in China's Science Journalism. Http:// www.scidev.net/en/science-communication/opinions/the-crisisin-chinas-science-journalism.html [accessed 24 February 2009].
Li, H., Aide, T., MA, Y., LiU, W. \& CaO, M. (2007) Demand for rubber is causing the loss of high diversity rain forest in SW China. Biodiversity and Conservation, 16, 1731-1745.

Li, W. \& S Mith, A.T. (2005) Dramatic decline of the threatened Ili pika Ochotona iliensis (Lagomorpha: Ochotonidae) in Xinjiang, China. Oryx, 39, 30-34.

Li, Y., Huang, C., Ding, P., Zheng, T. \& Wood, C. (2007) Dramatic decline of Francois' langur Trachypithecus francoisi in Guangxi Province, China. Oryx, 41, 38-43.

MaCKinnon, J.R. (2007) Enhancing the impact of academe on biodiversity conservation. Living Forests, 13, 18-19.

MacKinnon, J.R., Phillipps, K. \& He, F. (2000) A Field Guide to the Birds of China. Oxford University Press, Oxford, UK.

McGow An, P.J.K. (2007) Making science count: a World Pheasant Association perspective. Living Forests, 13, 26-29.

Ran, J., Du, B. \& YuE, B. (2009) Conservation of the Endangered giant panda Ailuropoda melanoleuca in China: successes and challenges. Oryx, 43, 176-178.

REAding, R.P. (2005) Is knowledge-provision enough? The relationship between values, attitudes and knowledge with respect to wildlife conservation. Living Forests, 10, 19-22.

Smith, A.T. \& Xie, Y. (2008) A Guide to the Mammals of China. Princeton University Press, Princeton, USA.

Tilson, R., Hu, D., Muntifering, J. \& Nyhus, P.J. (2004) Dramatic decline of wild south China tigers Panthera tigris amoyensis: field survey of priority tiger reserves. Oryx, 38 , $55-61$.

Turvey, S. (2008) Witness to Extinction: How We Failed to Save the Yangtze River Dolphin. Oxford University Press, Oxford, UK.

W Ang, S. \& XIE, Y. (2004) China Species Red List. Higher Education Press, Beijing, China.

Wang, X., Zhang, K., Wang, Z., Ding, Y., Wu, W. \& Huang, S. (2004) The decline of the Chinese giant salamander Andrias davidianus and implications for its conservation. Oryx, 38 , 197-202.

ZhanG, L., ZHU, G., Jones, G. \& ZHANG, S. (2009) Conservation of bats in China: problems and recommendations. Oryx, 43, 179-182.

\section{Note from the Editor-Conservation in China}

In July 2009 the Annual Meeting of the Society for Conservation Biology will be held in Beijing. Oryx has a history of publishing conservation research carried out in China and, to mark the meeting, we have brought together in this issue a range of articles on aspects of conservation in China. We have also solicited two perspective articles, on conservation of bats in China (pp. 179-182; to tie in with a global review of bats as bushmeat published in this issue, pp. 217-234) and on that perennial global symbol of conservation, the giant panda (pp. 176-178). 